\title{
COLLABORATION FOR THE ADVANCEMENT OF INDIRECT 3D PRINTING TECHNOLOGY
}

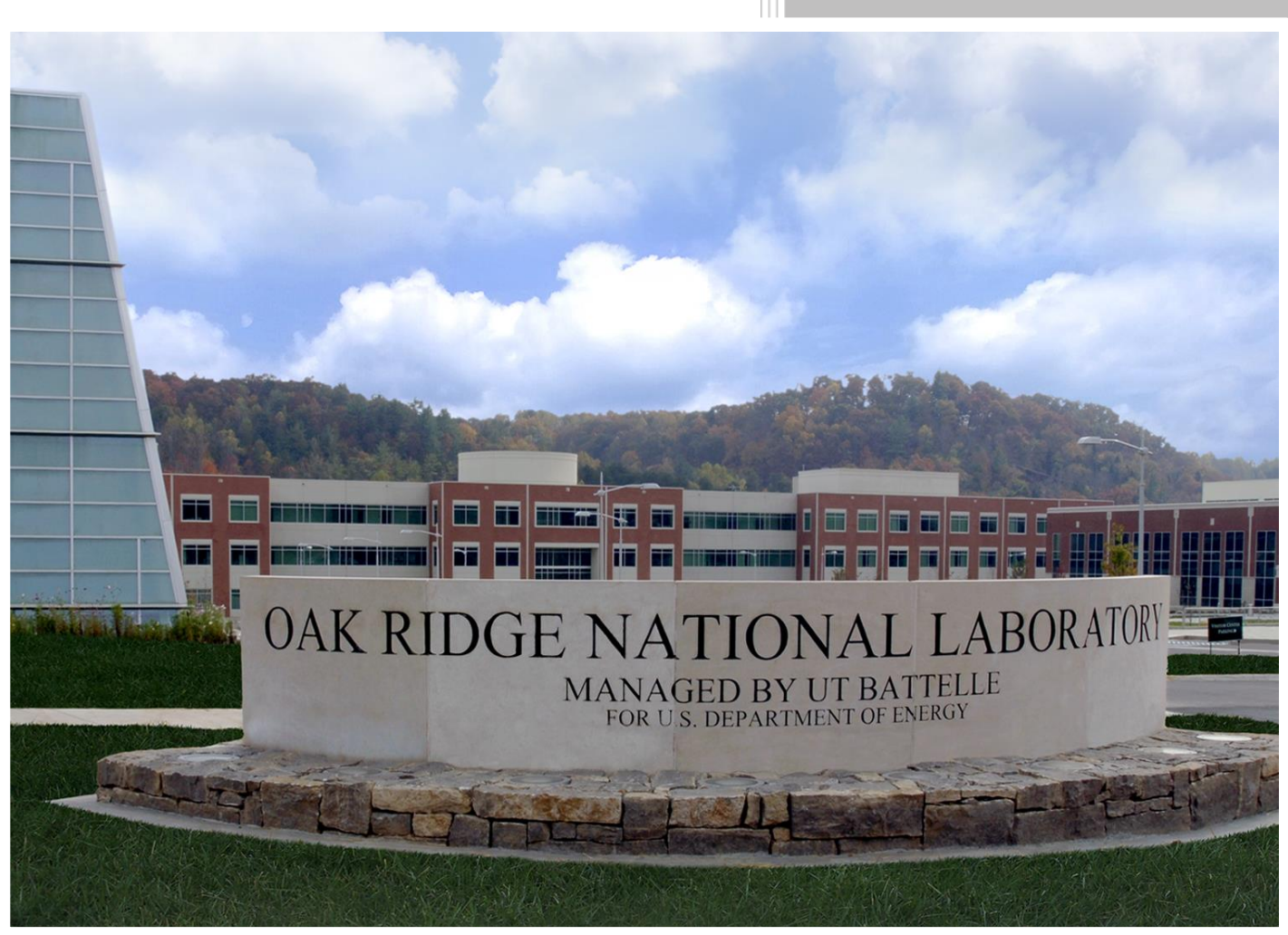

\section{CRADA FINAL REPORT NFE-15-05501}

Approved for Public Release. Distribution is Unlimited.
Zachary Cordero

Amy Elliott

June 14, 2016 


\section{DOCUMENT AVAILABILITY}

Reports produced after January 1, 1996, are generally available free via US Department of Energy (DOE) SciTech Connect.

Website http://www.osti.gov/scitech/

Reports produced before January 1, 1996, may be purchased by members of the public from the following source:

National Technical Information Service

5285 Port Royal Road

Springfield, VA 22161

Telephone 703-605-6000 (1-800-553-6847)

TDD 703-487-4639

Fax 703-605-6900

E-mail info@ntis.gov

Website http://www.ntis.gov/help/ordermethods.aspx

Reports are available to DOE employees, DOE contractors, Energy Technology Data Exchange representatives, and International Nuclear Information System representatives from the following source:

Office of Scientific and Technical Information

PO Box 62

Oak Ridge, TN 37831

Telephone 865-576-8401

Fax 865-576-5728

E-mail reports@osti.gov

Website http://www.osti.gov/contact.html

This report was prepared as an account of work sponsored by an agency of the United States Government. Neither the United States Government nor any agency thereof, nor any of their employees, makes any warranty, express or implied, or assumes any legal liability or responsibility for the accuracy, completeness, or usefulness of any information, apparatus, product, or process disclosed, or represents that its use would not infringe privately owned rights. Reference herein to any specific commercial product, process, or service by trade name, trademark, manufacturer, or otherwise, does not necessarily constitute or imply its endorsement, recommendation, or favoring by the United States Government or any agency thereof. The views and opinions of authors expressed herein do not necessarily state or reflect those of the United States Government or any agency thereof. 


\title{
COLLABORATION FOR THE ADVANCEMENT OF INDIRECT 3D PRINTING TECHNOLOGY
}

\author{
Zachary Cordero \\ Amy Elliott
}

Date Published:

June 14, 2016

\author{
Prepared by \\ OAK RIDGE NATIONAL LABORATORY \\ Oak Ridge, Tennessee 37831-6283 \\ managed by \\ UT-BATTELLE, LLC \\ for the \\ US DEPARTMENT OF ENERGY \\ under contract DE-AC05-00OR22725
}

Approved for Public Release 


\section{CONTENTS}

Page

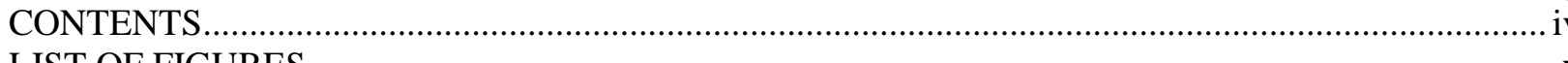

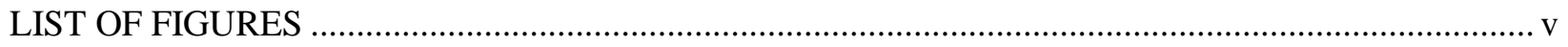

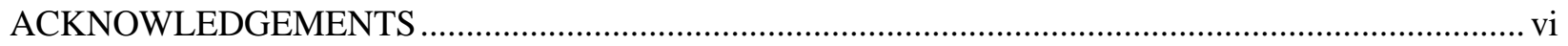

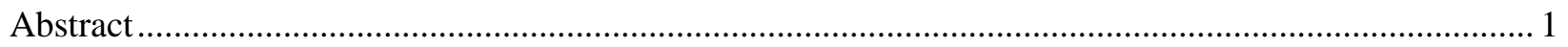

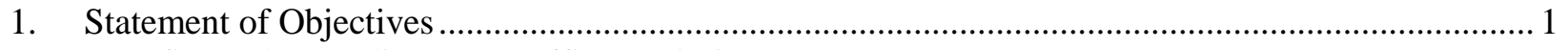

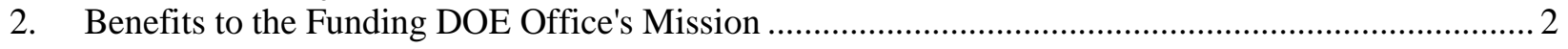

3. Technical Discussion of Work Performed by All Parties ............................................................... 2

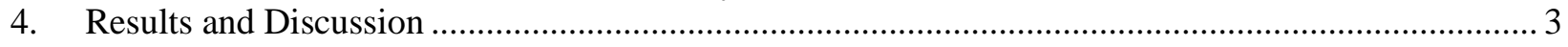

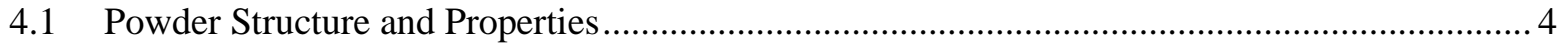

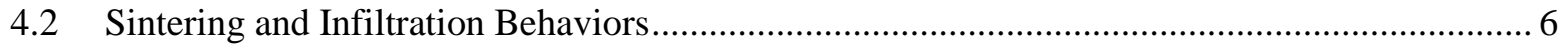

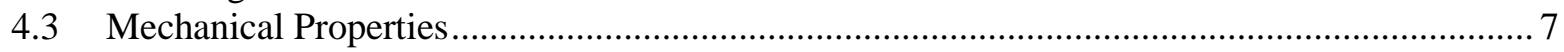

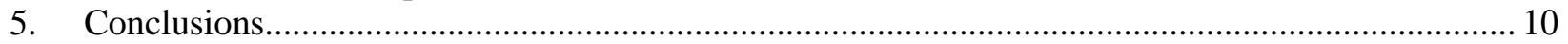

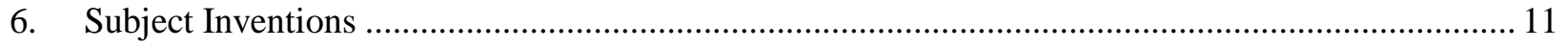

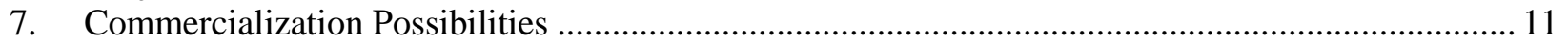

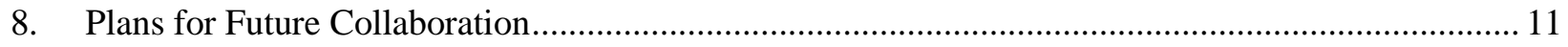

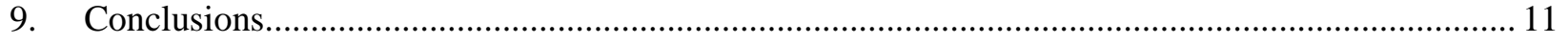




\section{LIST OF FIGURES}

Figure 1: Heating schedule used with the sintering and infiltration processes. The hold at $600{ }^{\circ} \mathrm{C}$ is to remove the binder.

Figure 2: Electron micrograph of cross-sectioned particles.................................................................. 5

Figure 3: XRD patterns collected from as-received and annealed powders. ......................................... 4

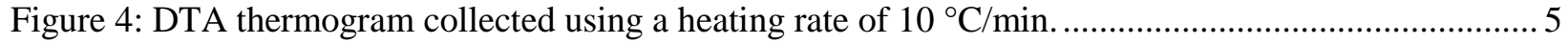

Figure 5: High-magnification backscatter electron micrograph of a cross-sectioned powder particle

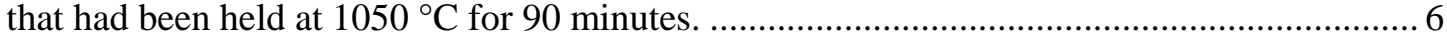

Figure 6: Backscatter electron micrograph of the infiltrated material................................................... 7

Figure 7: Representative load-displacement curves from bend tests on sintered and infiltrated

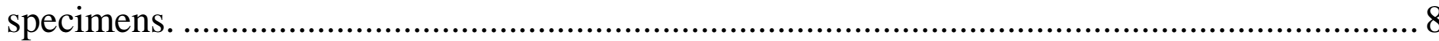

Figure 8: Electron micrographs of a) a sintered bend-test specimen's fracture surface and b) an infiltrated bend test specimen's fracture surface

Figure 9: Electron micrographs of an infiltrated specimen's fracture surface that show a) cleavage facets and b) microcracking. 


\section{ACKNOWLEDGEMENTS}

This CRADA NFE-15-05501was conducted as a Technical Collaboration project within the Oak Ridge National Laboratory (ORNL) Manufacturing Demonstration Facility (MDF) sponsored by the US Department of Energy Advanced Manufacturing Office (CPS Agreement Number 24761). Opportunities for MDF technical collaborations are listed in the announcement "Manufacturing Demonstration Facility Technology Collaborations for US Manufacturers in Advanced Manufacturing and Materials Technologies" posted at http://web.ornl.gov/sci/manufacturing/docs/FBO-ORNL-MDF-2013-2.pdf. The goal of technical collaborations is to engage industry partners to participate in short-term, collaborative projects within the Manufacturing Demonstration Facility (MDF) to assess applicability and of new energy efficient manufacturing technologies. Research sponsored by the U.S. Department of Energy, Office of Energy Efficiency and Renewable Energy, Advanced Manufacturing Office, under contract DEAC05-00OR22725 with UT-Battelle, LLC. 


\section{ABSTRACT}

Amorphous powders often possess high hardness values and other useful mechanical properties [1]. However, densifying these powders into complex shapes while retaining their unique properties is a challenge with standard processing routes. Pressureless sintering, for example, can densify intricate green parts composed of rapidly-solidified powders. But this process typically involves long exposures to elevated temperatures, during which the non-equilibrium microstructure of the powder can evolve towards lower energy configurations with inferior properties [2]. Pressure-assisted compaction techniques, by contrast, can consolidate green parts with simple shapes while preserving the microstructure and properties of the powder feedstock [3-5]. But parts made with these processes generally require additional post-processing, including machining, which introduces new challenges due to the high hardness of these materials.

One processing route that can potentially avoid these issues is Indirect 3D Printing (I-3DP; aka Binder Jetting) followed by melt infiltration. In I-3DP, an organic binder is used to join powder feedstock, layerby-layer, into a green part [6]. In melt infiltration, this green preform is densified by placing it in contact with a molten alloy that wets the preform and wicks into the pores as a result of capillary forces [7]. When these processes are paired together, they offer two key advantages for the densification of rapidlysolidified powders. The first advantage is that the timescale associated with melt infiltration is on the order of seconds for parts with $\mathrm{cm}$-scale dimensions [8]. So in many instances, infiltration requires only a brief thermal excursion that does not degrade the feedstock's microstructure. The second advantage is that the combination of binder-jet 3D printing and melt infiltration gives fully-dense net shape objects [9, $10]$, minimizing the need for subsequent post-processing.

In this work, fully-dense, net shape objects have been fabricated from an amorphous powder using I-3DP and molten bronze infiltration while maintaining the amorphous microstructure. X-ray diffraction, scanning electron microscopy, and differential thermal analysis were used to characterize the structural evolution of the powder feedstock during an infiltration heating cycle. Microindentation and bend tests were performed on the infiltrated material to evaluate its mechanical properties. It was found that infiltration improved both the ductility and strength of the sintered preforms by eliminating the stress concentration at the interparticle necks. The infiltrated material had an $11 \mathrm{GPa}$ Vickers hardness and moderate damage tolerance, making it well-suited for applications requiring hard, net shape parts.

\section{STATEMENT OF OBJECTIVES}

This phase 1 technical collaboration project (MDF-TC-2015-060) was begun on April 21, 2015 and was completed on May 31, 2016. The collaboration partner, The ExOne Company is a small business.

The scope of the Technical Collaboration Project has been divided into two phases. The first phase focuses on integrating an amorphous powdered metal system developed at ORNL for tooling applications to the ExOne I-3DP process. A proposed second phase involves developing a new binder system to eliminate the binder curing stage of the I-3DP process and also investigating the effects of the current binder system on sintering and infiltration. This document will detail efforts made in the first 12 months of the CRADA toward phase one: incorporating an ultra-hard stainless steel powder developed by ORNL into ExOne's I-3DP process.

The objectives of the first phase were to first develop printing process settings to achieve a near-net shape object from some batch-produced, amorphous powder. Second, printed parts underwent sintering and then infiltration with bronze and were evaluated for shrinkage during the process. The final part was evaluated 
for hardness, tensile strength, and other mechanical properties. The overall objective is to develop the processing parameters such that incorporating the amorphous alloy into ExOne's currently existing processes is immediately possible.

\section{BENEFITS TO THE FUNDING DOE OFFICE'S MISSION}

Additive Manufacturing (AM) of metals is a growing technology base that has the potential to significantly impact product realization in aerospace, automotive, and medical industries, among others. AM allows for the production of low-volume metal objects without the need for special tooling. Furthermore, AM technology can produce high-performance geometries that cannot be produced with traditional subtractive manufacturing methods. With powder bed fusion processes (Selective Laser Sintering, SLS, Selective Laser Melting, SLM, and Electron Beam Melting, EBM), many challenges exist due to thermal stresses within the printed parts, operator burden in completing the build process, low productivity rates, and overall cost of the equipment. Furthermore, developing process parameters for new materials in powder bed fusion processing is extremely difficult. Finally, with the exception of ExOne, the metal AM systems currently available are produced solely by manufacturers foreign to the United States.

Due to these negatives, many companies are looking to ExOne's Indirect 3D printing (Indirect 3DP) for their metal AM production needs. Currently, however, Indirect 3DP is limited to a stainless steel-bronze matrix as its only fully-dense material. This project seeks to expand the material selection of Indirect 3D Printing by introducing an amorphous alloy as a replacement to the stainless steel, providing significantly higher hardness and thus opening the technology up to high-wear tooling applications. Overall, the advancement of Indirect 3D printing material selection could lead to the adoption of AM technology by main-stream manufacturing industry and lead to higher US global manufacturing competitiveness.

\section{TECHNICAL DISCUSSION OF WORK PERFORMED BY ALL PARTIES}

A $100-\mathrm{kg}$ batch of rapidly-solidified powder was prepared using nitrogen gas-atomization. The composition of the powder is given in Table 1.

Table 1: Composition listed in wt $\%$ of the gas-atomized powder.

\begin{tabular}{cccccccc}
\hline $\mathrm{Fe}$ & $\mathrm{Cr}$ & $\mathrm{Mo}$ & $\mathrm{V}$ & $\mathrm{B}$ & $\mathrm{C}$ & $\mathrm{Si}$ & $\mathrm{O}$ \\
\hline 49 & 18.6 & 15.8 & 8.9 & 3.4 & 3.3 & 1.08 & 0.02 \\
\hline
\end{tabular}

This alloy was designed so that when it is heated, thermally-stable carbides and borides precipitate and prevent grain growth [11]. The as-received powder was sieved to remove particles with diameters larger than $45 \mu \mathrm{m}$ which can interfere with printing.

The structure of the powder was characterized using x-ray diffraction (XRD) and scanning electron microscopy (SEM). The XRD patterns were collected on a PANALYTICAL X'Pert PRO diffractometer using Mo Ka radiation. SEM samples were prepared by first mounting the particles in epoxy and then cross-sectioning them using standard metallographic grinding and polishing techniques. The samples were imaged using a Hitachi S3400 scanning electron microscope (SEM) operated at $20 \mathrm{kV}$ and equipped with an energy-dispersive spectroscopy (EDS) detector. The structural evolution of the powder was evaluated using differential thermal analysis (DTA). $120 \mathrm{mg}$ samples were heated to $1300{ }^{\circ} \mathrm{C}$ at 10 ${ }^{\circ} \mathrm{C} / \mathrm{min}$ in a TA Instruments Q600 under flowing Ar. 
An ExOne Lab 3D printer was used to print green parts from the gas-atomized powder. All of the prints were performed using a $100 \mu \mathrm{m}$ layer thickness and a diethylene glycol binder. After the prints were completed, the binder was cured by heating the entire powder bed to $200{ }^{\circ} \mathrm{C}$ for $2 \mathrm{hrs}$. The green parts were then de-powdered.

The densification behavior of the 3D printed parts was investigated by printing $6 \mathrm{~mm}$ diameter and $8 \mathrm{~mm}$ high cylinders printed with their axes of rotation parallel to the build direction. These green bodies were subsequently processed in one of two ways: either they were sintered, or they were infiltrated with $\mathrm{Cu}$ 10Sn, wt $\%$ bronze. Both the sintered and infiltrated specimens were subjected to the same heating schedule, shown in Figure 1. This schedule was based on one that had been developed for 420 stainless steel powders. The samples were infiltrated by placing them in direct contact with a reservoir of molten bronze. The sintering and infiltration processes were conducted under flowing $\mathrm{Ar}+4 \% \mathrm{H} 2$. Following sintering and infiltration, the dimensions of each cylinder were measured at room temperature using a micrometer.

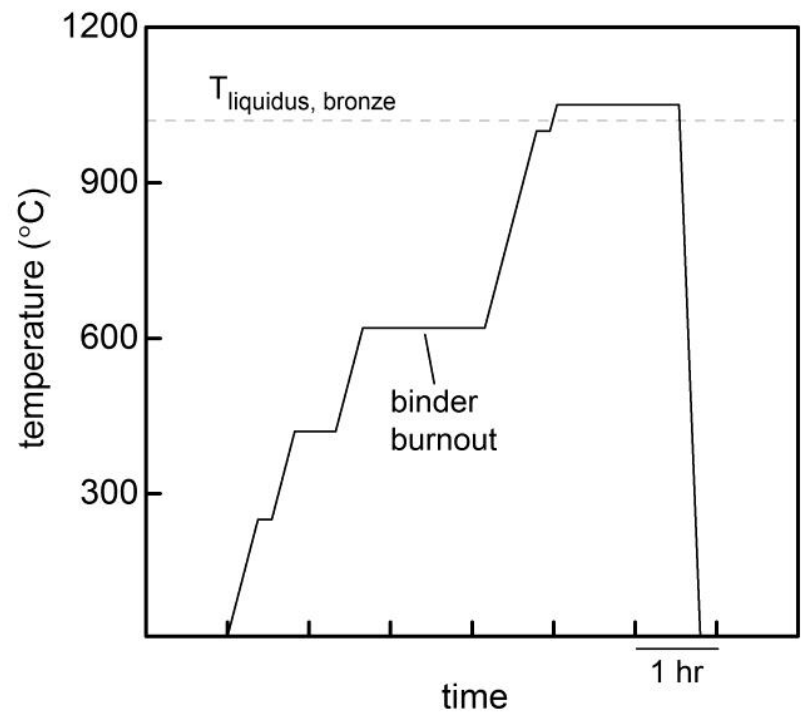

Figure 1: Heating schedule used with the sintering and infiltration processes. The hold at $600{ }^{\circ} \mathrm{C}$ is to remove the binder.

Sintered and infiltrated flat specimens $6 \mathrm{~cm}$ long with 4 x $10 \mathrm{~mm}$ cross-sectional dimensions were also prepared for three-point bend tests. The bend tests were performed on a servohydraulic universal test machine. The span was $40 \mathrm{~mm}$, the displacement rate was $0.5 \mathrm{~mm} / \mathrm{min}$, and the displacement was measured from the crosshead.

These sintered and infiltrated specimens were cross-sectioned and imaged in the same manner as the loose powder particles. In addition, the Vickers microhardness of these cross-sectioned specimens was measured using a LECO microhardness tester with a hold time of $15 \mathrm{~s}$. Low loads (10-50 gf) were used to measure the microhardness of individual phases, while higher loads ( $5 \mathrm{kgf}$ ) were used to measure the effective macrohardness.

\section{RESULTS AND DISCUSSION}




\subsection{POWDER STRUCTURE AND PROPERTIES}

Figure 2 shows an XRD pattern collected from the rapidly-solidified powder particles. The broad, lowintensity halo between 15 and $25^{\circ} 2 \theta$ is evidence of an amorphous phase. The Bragg peaks overlaid on this halo are assigned to $\alpha-\mathrm{Fe}, \mathrm{VC}$, a M23C6 carbide, and a M3B2 boride that is typically molybdenumrich.

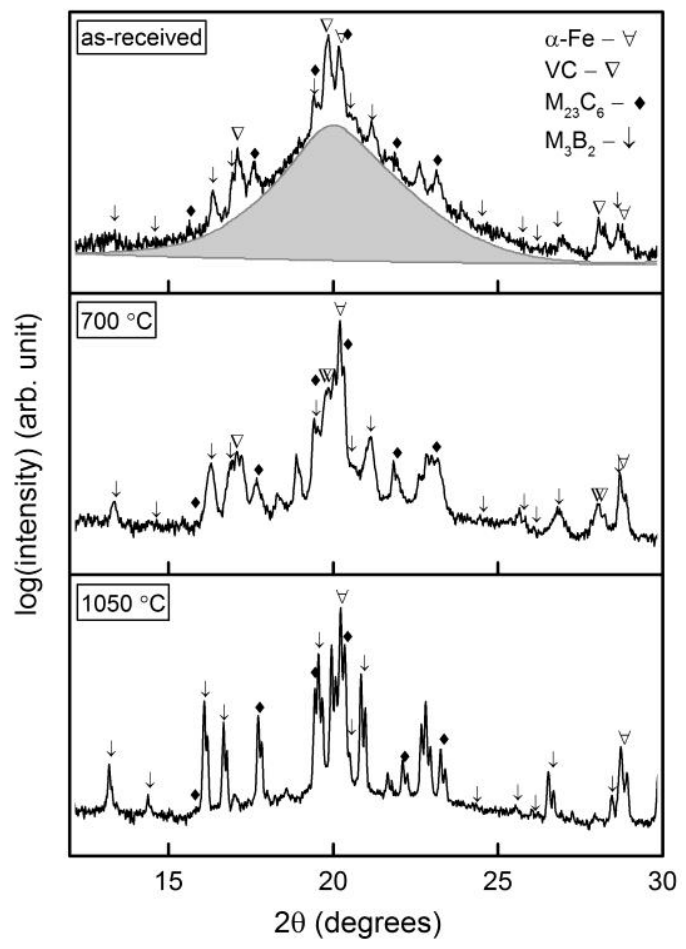

Figure 2: XRD patterns collected from as-received and annealed powders.

After sieving, the powder had a mean particle size of $10 \mu \mathrm{m}$ according to quantitative stereological measurements. The SEM micrograph of two cross-sectioned particles in Figure 3 shows how the internal structure of the particles depended on their size: the larger particle on the left contains clearly distinguishable regions that correspond to multiple distinct phases, whereas the smaller particle is featureless. Based on the homogeneous structure of these smaller particles, the more rapid cooling rate of finer particles [1], and the broad halo in the XRD pattern, it is inferred that these smaller particles were amorphous. Inspection of many cross-sectioned particles revealed that only particles with diameters greater than $\sim 5 \mu \mathrm{m}$ crystallized during atomization. 


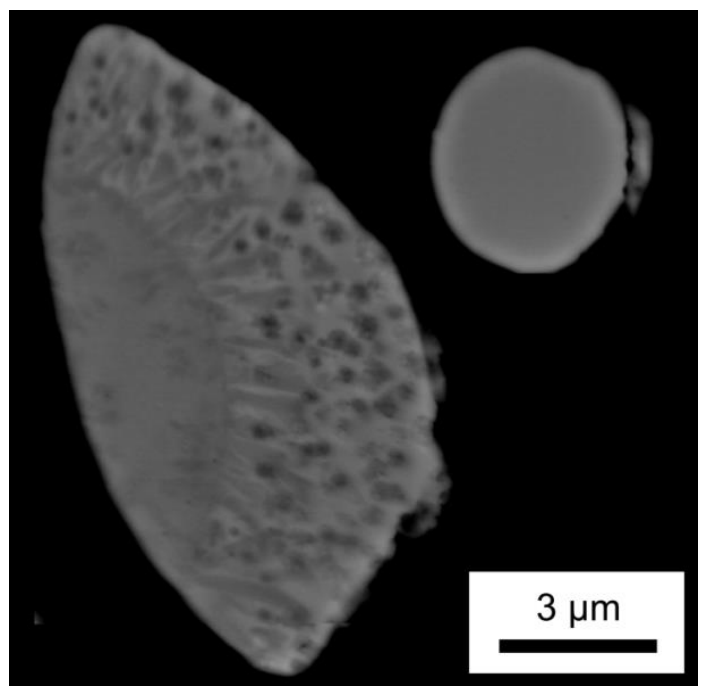

Figure 3: Electron micrograph of cross-sectioned particles.

Figure 4 shows a representative thermogram from one of the differential thermal analysis (DTA) experiments used to study the structural evolution of this alloy. This curve features two irreversible exothermic reactions with peak temperatures at 690 and $800{ }^{\circ} \mathrm{C}$ as well as an endotherm between 1100 and $1180{ }^{\circ} \mathrm{C}$ associated with melting. To identify the solid-state reactions associated with each of the exotherms, XRD patterns were collected from powders that had been briefly heated to 700 and $1050{ }^{\circ} \mathrm{C}$. These patterns are presented in Figure 2, and they show that the exotherm at $690{ }^{\circ} \mathrm{C}$ is the result of a devitrification reaction, while the exotherm at $800^{\circ} \mathrm{C}$ is due to the decomposition of the $\mathrm{VC}$ phase.

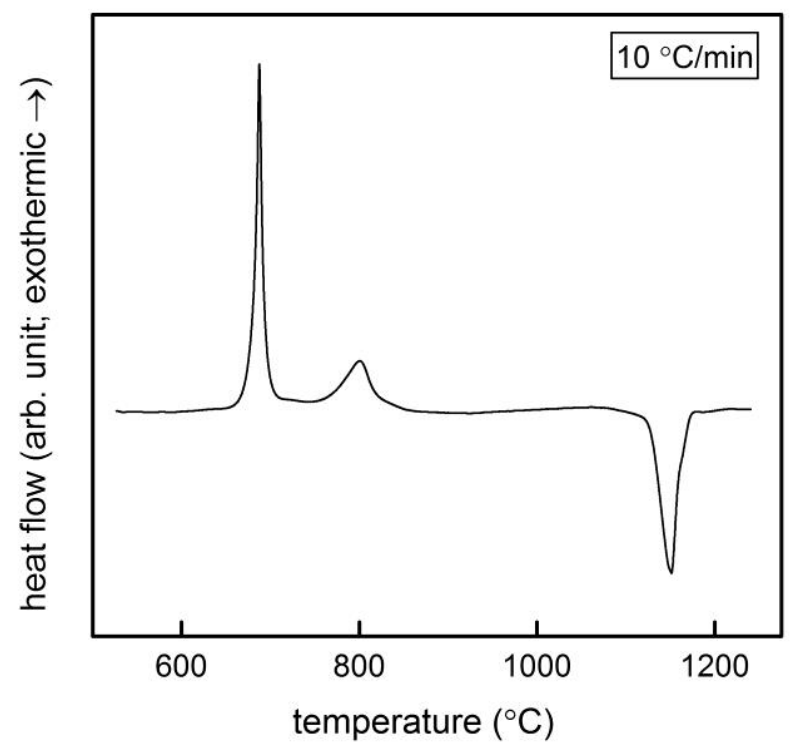

Figure 4: DTA thermogram collected using a heating rate of $10^{\circ} \mathrm{C} / \mathrm{min}$.

Figure 5 is a high-magnification backscatter electron micrograph of a particle that had been heated to $1050{ }^{\circ} \mathrm{C}$ for 90 minutes, the same temperature and time used in the sintering and infiltration processes. Quantitative EDS showed that the bright regions in Figure 5 had a high concentration of molybdenum, meaning they were likely the boride phase, and that the surrounding matrix was $\alpha$-Fe. Stereological measurements showed that the volume fraction of the boride phase was 0.2 and that this phase had a mean circular equivalent diameter of $0.5 \mu \mathrm{m}$. Using these values with the Zener relation [13], the grain size of 
the ferrite matrix was estimated to be $1.7 \mu \mathrm{m}$. In light of these results, it seems that this alloy can retain a fine structure even during prolonged exposures to high homologous temperatures. Additionally, all of the annealed particles had a similar structure, so the variations in the as-received powder were eliminated on heating.

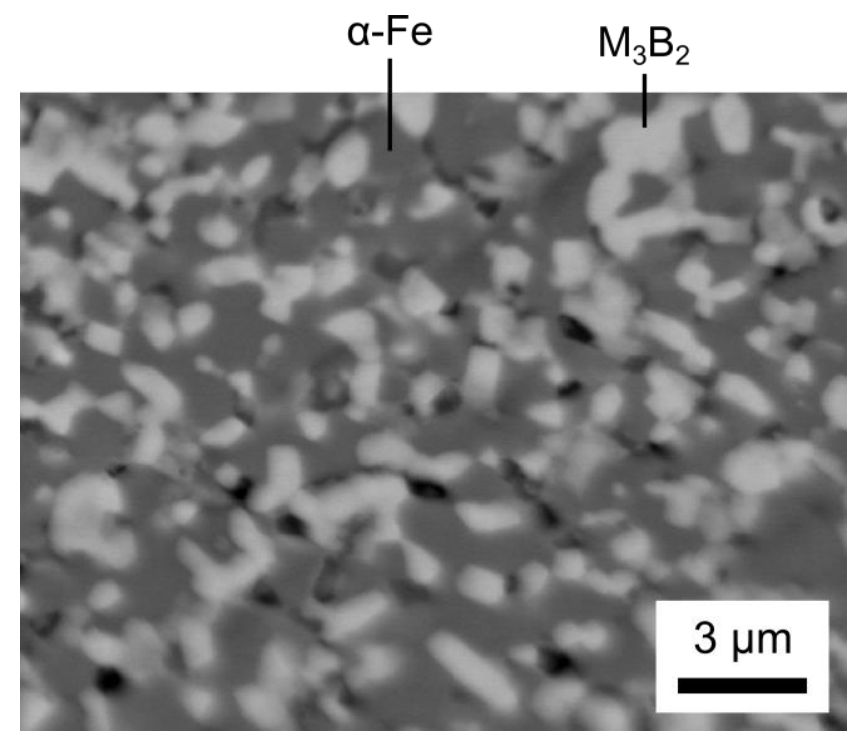

Figure 5: High-magnification backscatter electron micrograph of a cross-sectioned powder particle that had been held at $1050{ }^{\circ} \mathrm{C}$ for 90 minutes.

\subsection{SINTERING AND INFILTRATION BEHAVIORS}

The sintered cylinders exhibited a radial shrinkage of $1.1 \%$ and an axial shrinkage of $1.4 \%$. This anisotropic shrinkage is likely a result of the powder spreading operation, which imparts orthotropic symmetry to the green part. With regards to process design, it is important that this alloy densifies near the liquidus temperature of the bronze infiltrant, since this helps the preform resist slumping during infiltration. The axial shrinkage of the infiltrated cylinders was $0.7 \%$, half that of the sintered cylinders. Additionally, the infiltrated cylinders swelled $0.4 \%$ in the radial direction due to gravitational effects. Quantitative stereological measurements showed that the porosities of the sintered and infiltrated cylinders were $33 \%$ and $2 \%$, respectively, and that the volume fraction of bronze in the infiltrated cylinders was 0.35 .

Figure 6 is a backscatter electron micrograph of one of the infiltrated cylinders. In this micrograph, the bronze infiltrant appears light and the sintered skeleton dark. This micrograph shows the spherical microvoids that were distributed evenly throughout the infiltrant and the sintered skeleton. This micrograph also shows two other important features of the infiltrated material's structure. First, there is a several $\mu \mathrm{m}$-thick denuded zone at the interface between the infiltrant and the sintered skeleton where the $\alpha$-Fe matrix has dissolved. Second, some regions of the sintered skeleton are free of the boride phase. According to EDS measurements, the composition of these boride-free regions was $\mathrm{Fe}-6 \mathrm{Si}-5 \mathrm{Cr}-5 \mathrm{Cu}$, at $\%$, which is distinct from the nominal composition of the powder feedstock. These two features were only found in the infiltrated specimens, suggesting these boride-free deposits formed because $\alpha$-Fe dissolved into the molten bronze and then reprecipitated in a second location. 


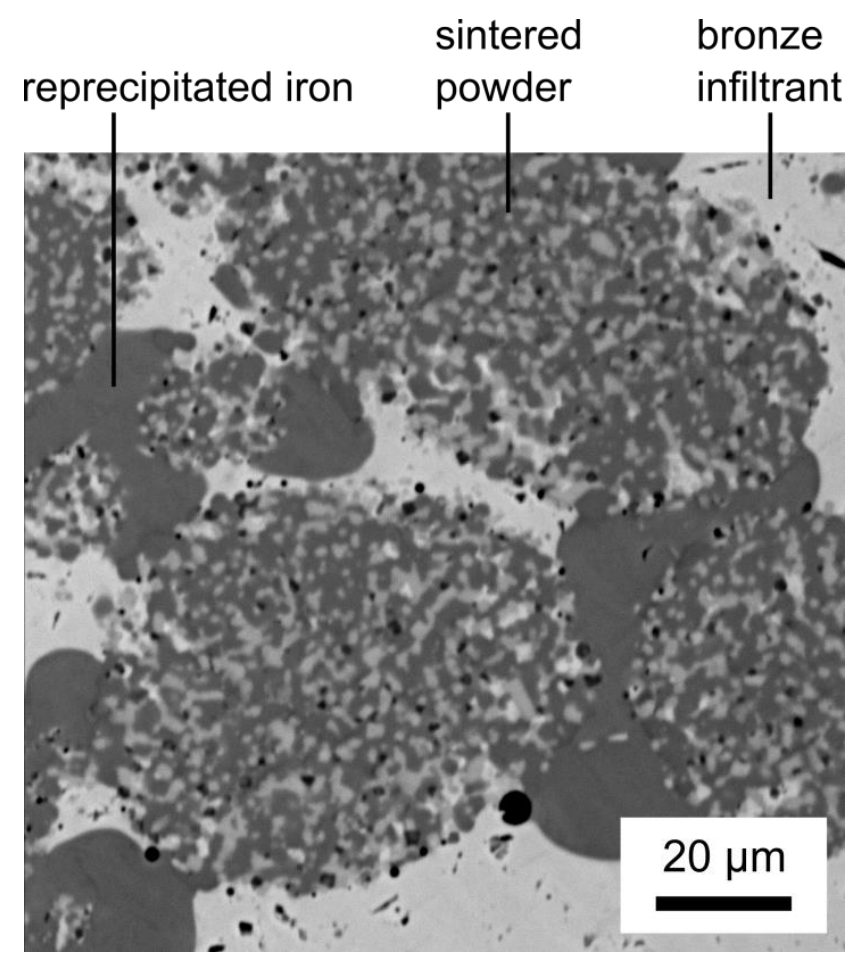

Figure 6: Backscatter electron micrograph of the infiltrated material.

\subsection{MECHANICAL PROPERTIES}

The Vickers microhardness of the sintered skeleton was $17 \mathrm{GPa}$. This is almost an order of magnitude greater than the expected hardness of pure iron with a grain size of $2 \mu \mathrm{m}$, according to the Hall-Petch data in Ref [14]. Thus, the high hardness of the sintered skeleton is most likely a result of the high volume fraction of the boride phase. The bronze-infiltrated material had a macrohardness of $11 \mathrm{GPa}$, which is close to the volume average hardness of the sintered skeleton and the bronze infiltrant, which has a Vickers hardness of $500 \mathrm{MPa}$ in the annealed state according to Ref [15]. Table 2 includes the mechanical properties for the printed amorphous steel infiltrated with bronze and the standard ExOne materials: 420 and 316 Stainless Steels infiltrated with bronze (baseline). The results show comparable values for yield strength, tensile strength, and elongation with a slight decrease in density between the baseline stainless steels and the amorphous steel. The notable property of the amorphous steel is 11 GPa hardness value, which is over five times the hardness for the baseone ExOne materials.

Table 2: Comparison of Mechanical Properties

\begin{tabular}{|c|c|c|c|c|}
\hline & \multirow{2}{*}{\multicolumn{2}{|c|}{ 420SS/Bronze }} & \multirow{3}{*}{ 316SS/Bronze } & \multirow{3}{*}{$\begin{array}{c}\text { Amorphous } \\
\text { /Bronze }\end{array}$} \\
\hline & & & & \\
\hline & Annealed & Non-Annealed & & \\
\hline Tensile Strength (MPa) & 496 & 682 & 580 & 600 \\
\hline Yield Strength (MPa) & 427 & 455 & 283 & 500 \\
\hline Elastic Modulus (GPa) & 147 & 147 & 135 & - \\
\hline Elongation (\%) & 7 & 2.3 & 14.5 & $\sim 2 \%$ \\
\hline Hardness (GPa) & 2 & 2 & 1 & 11 \\
\hline Fractional Density (\%) & $95 \%+$ & $95 \%+$ & $95 \%+$ & $98 \%+$ \\
\hline Density $\left(\mathrm{g} / \mathrm{cm}^{\wedge} 3\right)$ & 7.86 & 7.86 & 7.86 & 7.28 \\
\hline
\end{tabular}


Figure 7 presents representative load-displacement curves from bend tests on sintered and infiltrated specimens. The sintered specimens' load-displacement curves exhibit classic brittle behavior. In contrast, the non-linearity in the infiltrated specimens' load-displacement curves indicates that these materials underwent some plastic deformation prior to failure. Thus infiltration appears to have slightly improved the ductility. Comparison of these load-displacement curves shows that the infiltrated specimens were much stiffer and stronger than the sintered specimens: the infiltrated specimens had an average transverse rupture strength $(\sigma \mathrm{TRS})$ of $600 \mathrm{MPa}$, which was nearly four times higher than that of the sintered specimens. The infiltrated specimens were nonetheless much weaker than was expected based on their macrohardness.

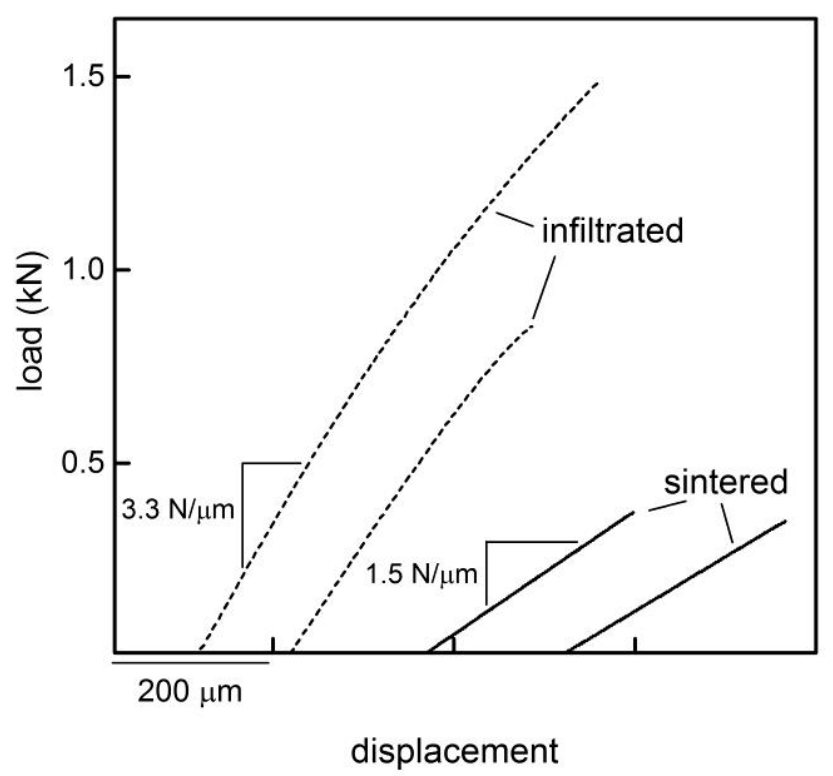

Figure 7: Representative load-displacement curves from bend tests on sintered and infiltrated specimens.

The fracture surfaces of the sintered and infiltrated bend test specimens were imaged in order to clarify how infiltration resulted in an almost four-fold increase in the $\sigma$ TRS. The fractograph of a sintered bend test specimen in Figure 8a shows that this sample failed by brittle fracture at the interparticle necks. By contrast, the fractograph of the infiltrated specimen in Figure 8b shows that this sample failed primarily by trans-particle crack propagation. 

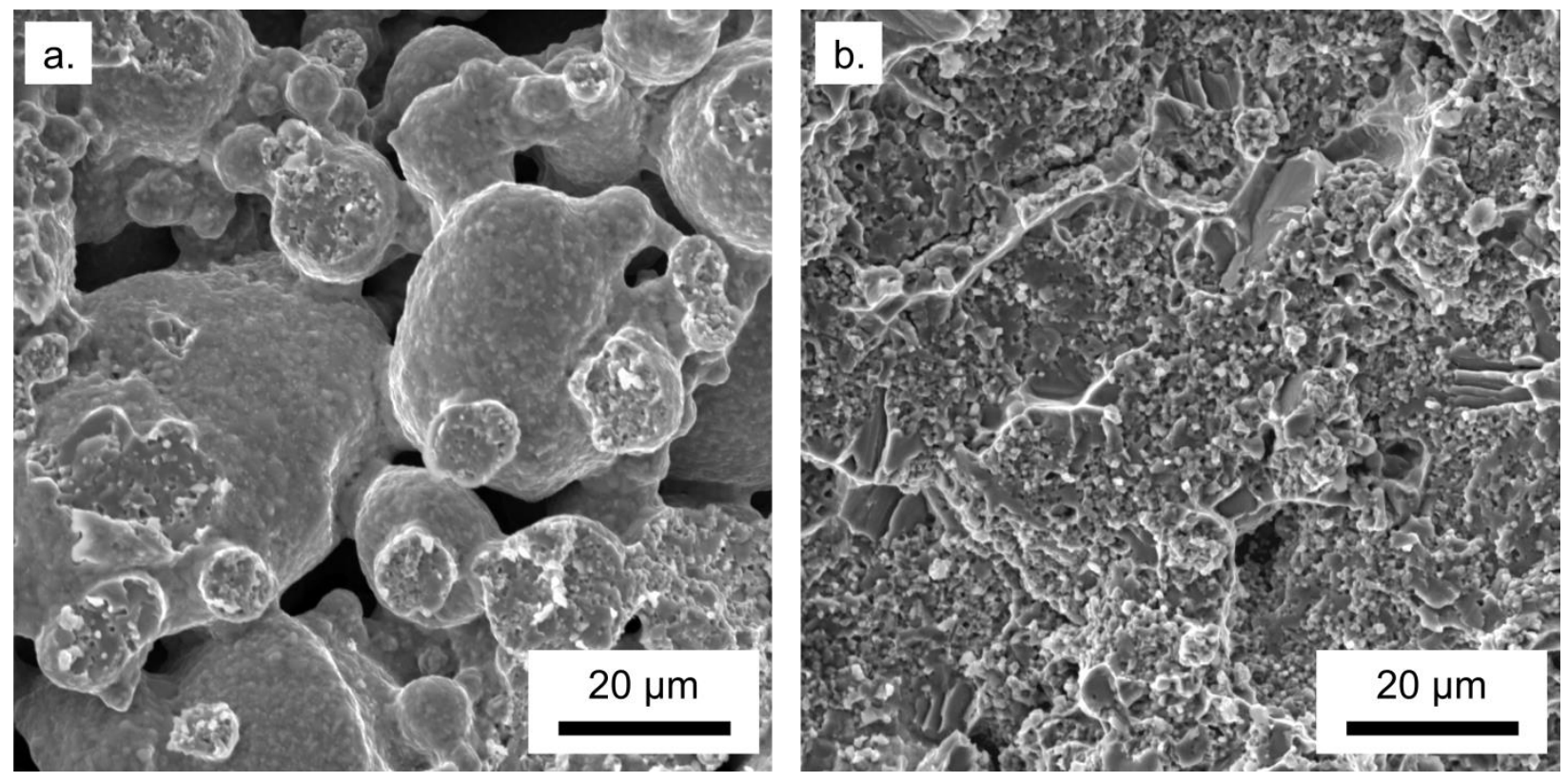

Figure 8: Electron micrographs of a) a sintered bend-test specimen's fracture surface and b) an infiltrated bend test specimen's fracture surface

These disparate failure modes suggest that infiltration eliminated the stress concentration at the interparticle necks. The magnitude of the neck stress concentration factor (S) can be estimated using

$\mathrm{S} \approx 1+\sqrt{\frac{\mathrm{x}}{\rho}}$

where $\mathrm{x}$ is the average neck radius and $\rho$ is the average radius of curvature of the neck [16]. Quantitative stereological measurements on the sintered specimens gave $x=4 \mu \mathrm{m}$ and $\rho=1 \mu \mathrm{m}$ so that $\mathrm{S} \approx 3$. Thus, eliminating the stress concentration at the necks by infiltration should have increased the $\sigma$ TRS by a factor of three, which is consistent with the strengthening increment seen in the bend tests.

Closer inspection of the fracture surfaces of the infiltrated specimens revealed two more interesting features. First, the fracture surface contained large cleavage facets, an example of which is shown in Figure 9a. Using EDS, these regions were identified as reprecipitated iron deposits. The brittle behavior of these deposits means they should be avoided, and one way to eliminate them is to use a shorter infiltration time. Second, microcracks like the one shown in Figure $9 \mathrm{~b}$ intersected the fracture surface in many places. These microcracks had an average length of $15 \mu \mathrm{m}$, which is similar to the particle length scale. Because these cracks mostly appeared at the interface between the infiltrant and the sintered skeleton, it seems that the infiltrant played a dual role, simultaneously strengthening and toughening the alloy while also introducing crack nucleation sites. 

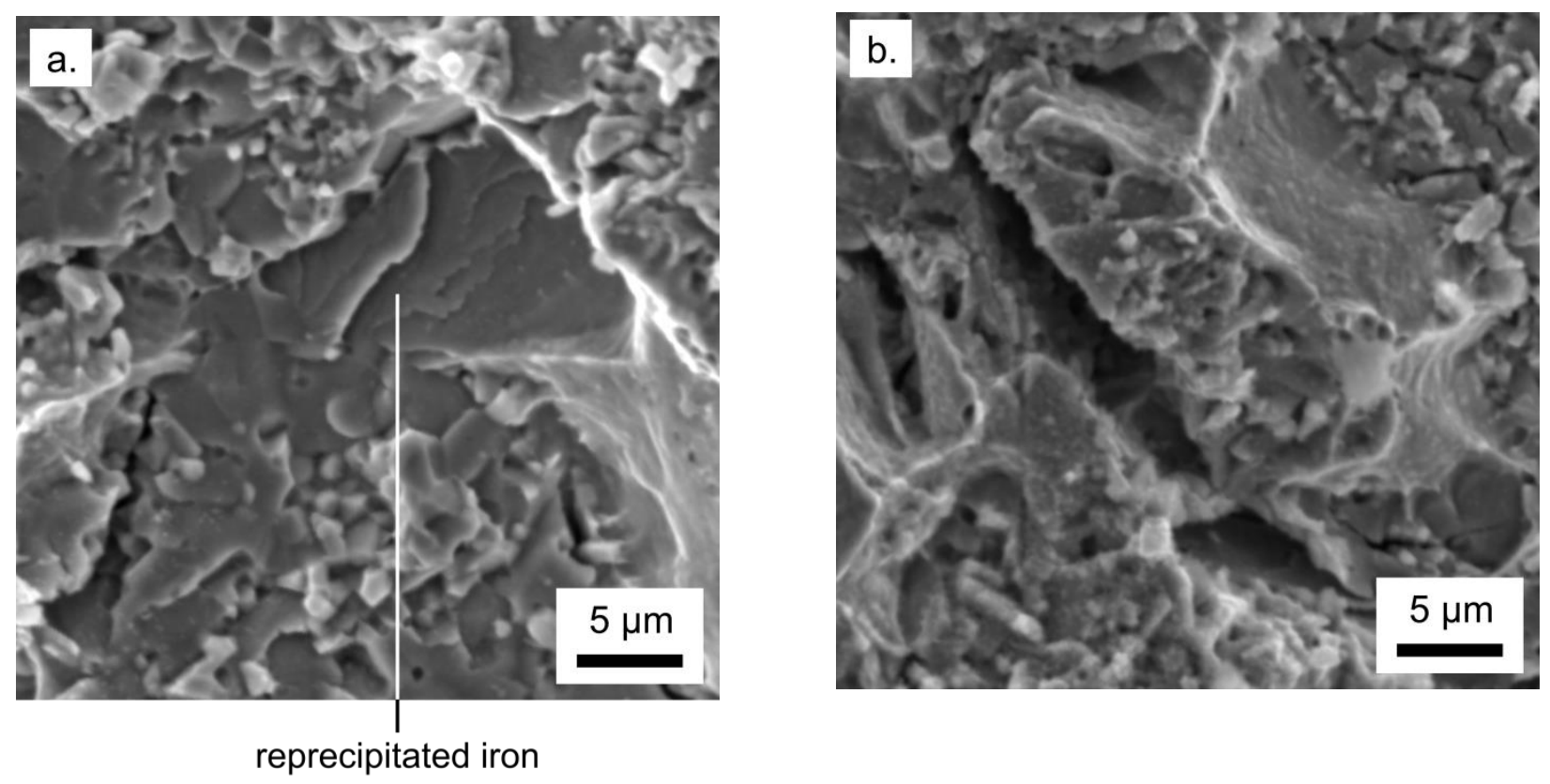

Figure 9: Electron micrographs of an infiltrated specimen's fracture surface that show a) cleavage facets and b) microcracking.

\section{CONCLUSIONS}

A rapidly-solidified powder was processed using binder-jet 3D printing and molten bronze infiltration. The following conclusions were drawn from a systematic analysis of the microstructure and mechanical properties of the infiltrated material:

The powder feedstock sinters and undergoes a series of solid state reactions on heating to the infiltration temperature. The structure that it ultimately develops features a dispersion of sub-micron boride dispersoids in an $\alpha$-Fe matrix.

During infiltration, some of the $\alpha$-Fe matrix dissolves into the molten bronze and then re-precipitates at a second location. Inspection of the fracture surface of the infiltrated material showed that this reprecipitated $\alpha$-Fe was brittle and cleaved, and should therefore be avoided by using shorter infiltration cycles.

The infiltrated material had a macrohardness of $11 \mathrm{GPa}$ and a transverse rupture strength of $600 \mathrm{MPa}$, which was four times higher than that of the sintered material. Examination of the sintered and infiltrated materials' fracture surfaces showed that infiltration mainly affected the transverse rupture strength by eliminating the stress concentration at the interparticle necks.

Applications for the infiltrated material are likely to be in harsh environments where net-shape parts with high hardnesses are required.

Industry Partner Involvement: ExOne provided advisement on sintering cycle, bronze infiltration procedure, printing settings for the different-shaped powder, and donated equipment as part of the costshare for this project. 


\section{SUBJECT INVENTIONS}

Potentially, the 3D printing of high-entropy alloys via binder jetting could be patentable. Further investigation will be needed to explore this possibility.

\section{COMMERCIALIZATION POSSIBILITIES}

ExOne provides metal additive manufacturing services to aerospace, oil and gas, and mining industries, among others. Currently, the applications in which they can provide metal parts for these industries are limited by the material properties of their current material system, which is printed stainless steel in a bronze matrix. By replacing the stainless steel with a harder material like the amorphous alloy in this study, ExOne can expand their services to provide parts for high-wear applications.

\section{PLANS FOR FUTURE COLLABORATION}

ORNL plans to continue working with ExOne to advance Binder Jet technology toward the goal of achieving printed parts with a wide range of material properties suitable for vast industrial application. Future work includes exploring stronger binders to enable more complex geometries and new infiltrates to replace bronze as the material matrix.

\section{CONCLUSIONS}

In this work, a commercially-available amorphous alloy was incorporated into the binder jetting AM process for the purpose of producing harder AM parts for high-wear applications. The alloy was printed via binder jetting and infiltrated with bronze via the current process developed for stainless steel. Results show hardness has been increased by a factor of 5 for the currently-existing metals provided by ExOne.

\section{References}

[1] E.Y. Gutmanas, Progress in Materials Science, 34 (1990) 261-366.

[2] G. Thursfield, M.J. Stowell, Journal of Materials Science, 9 (1974) 1644-1660.

[3] E. Ayman, U. Junko, K. Katsuyoshi, Acta Materialia, 59 (2011) 273-282.

[4] P. Kasiraj, T. Vreeland, R.B. Schwarz, T.J. Ahrens, Acta Metallurgica, 32 (1984) 1235-1241.

[5] N.N. Thadhani, A.H. Mutz, T. Vreeland, Acta Metallurgica, 37 (1989) 897-908.

[6] E.M. Sachs, M.J. Cima, P. Williams, D. Brancazio, J. Cornie, Journal of Engineering for Industry, 114 (1992) 481-488.

[7] K.A. Semlak, F.N. Rhines, Trans AIME, 212 (1958) 325-331.

[8] A.M. Lorenz, E.M. Sachs, S.M. Allen, Metallurgical and Materials Transactions A, 35 (2004) 641653.

[9] S. Michaels, E.M. Sachs, M.J. Cima, in: Solid Freeform Fabrication Symposium, 1992, pp. 244-250.

[10] S.M. Allen, E.M. Sachs, Metals and Materials, 6 (2000) 589-594.

[11] W.H. Peter, R.R. Dehoff, P.J. Blau, Y. Yamamoto, W. Chen, A.S. Sabau, A. Klarner, in: D.o. Energy

(Ed.), Oak Ridge National Laboratory, 2013.

[12] G.W. Scherer, Journal of the American Ceramic Society, 69 (1986).

[13] E.E. Underwood, (1970).

[14] J.S.C. Jang, C.C. Koch, Scripta Metall. Mater., 24 (1990) 1599-1604.

[15] W.-Y. Li, C.-J. Li, H. Liao, C. Coddet, Applied surface science, 253 (2007) 5967-5971. 
[16] F.A. McClintock, A.S. Argon, Mechanical behavior of materials, Addison-Wesley, Boston, MA, 1966. 